\title{
PROPOSTA DE ESQUEMA ANALÍTICO PARA O PROCESSO ESTRATÉGICO - O CASO DE UMA UNIVERSIDADE PÚBLICA
}

\section{FERNANDO ANTÔNIO COLARES PALÁCIOS}

Doutor em Administração pela Faculdade de Economia, Administração e Contabilidade da Universidade de São Paulo (FEA-USP).

Professor titular do Programa de Pós-Graduação em Administração da Universidade da Amazônia (Unama) e Universidade do Estado do Pará (Uepa). Avenida Alcindo Cacela, 287, bloco C, $2^{\circ}$ andar, Umarizal, Belém - PA - Brasil - CEP 66060-902

E-mail:pppe@unama.br 


\section{RESUMO}

Captar a dinâmica de como ocorrem os eventos estratégicos e identificar fatores externos e internos à organização envolvidos em sua realização vem mobilizando há anos parte dos pesquisadores do campo. O objetivo do artigo é apresentar proposta de esquema analítico sobre processo estratégico em uma universidade pública, no caso, a elaboração e implementação do Projeto Pedagógico Institucional (PPI) de um novo campus. Do ponto de vista analítico, parte-se de abordagem menos linear para mais interpretativa de estratégia, na qual sua formação ocorre por meio de interação social, considerando as crenças e as interpretações comuns dos membros da organização. Especificamente, busca-se saber como determinadas estratégias surgem e quais aspectos conjunturais influenciam na definição de prioridades e nos processos de tomada de decisão de seus implementadores. A proposta está fundamentada, no campo sociológico, nas teorias de estruturação e de transformação social, e no campo organizacional, em perspectiva processual e prática. O esquema foi construído, aplicado e validado quando do episódio da implantação de um novo campus universitário por meio de pesquisa qualitativa, utilizando a metodologia de estudo de caso. Neste artigo, apresenta-se a etapa de elaboração do esquema. Ao se empreender uma busca teórica e metodológica capaz de subsidiar descrições e explicações sobre um processo dinâmico de criação e implementação de estratégia em uma universidade pública, procurava-se encontrar um meio que apreendesse o fenômeno estratégico de maneira integrada, e não de forma compartimentalizada, como se observa em muitos estudos. Por meio do esquema, foi possível perceber as ações práticas dos agentes e a sua influência no processo estratégico, e o quanto a maneira como os eventos se desenvolvem influencia as práticas dos estrategistas. Foi possível intuir que agentes em universidades públicas utilizam o poder de sua expertise para construir um contexto de atuação favorável aos seus interesses, mesmo que isso implique mudanças significativas no PPI. Para o analista organizacional, o esquema é capaz de definir níveis de análise de forma integrada, delimitar temporalmente as ações e delinear procedimentos metodológicos. 


\section{PALAVRAS-CHAVE}

Estratégia. Processo estratégico. Esquema analítico. Universidade pública. Construção social.

\section{INTRODUÇÃO}

A análise do processo estratégico em organizações complexas como as universidades públicas tem apresentado para os pesquisadores o desafio de encontrar caminhos metodológicos capazes de apreender a realidade como ocorre de fato.

Processo estratégico refere-se ao modo como as estratégias da organização são formuladas (elaboradas) e implementadas (Bulgacov, Souza, Prohmann, Coser, \& Baraniuk, 2007). Do ponto de vista analítico, parte-se de uma abordagem menos linear (uma ação corresponde a um dado resultado) para uma mais interpretativa de estratégia (Chaffee, I985), na qual a formação da estratégia é um processo de interação social, fundamentado nas crenças e nas interpretações comuns dos membros de uma organização (Mintzberg, Ahstrand, \& Lampel, 2000). Especificamente, busca-se saber como determinadas estratégias surgem e quais aspectos conjunturais influenciam na definição de prioridades e nos processos de tomada de decisão de seus implementadores.

O sistema social a ser analisado, a universidade pública, é composto por diversos grupos e estruturas interconectados de forma mais ou menos autônoma, constituindo o que se denominou de burocracia profissional (Mintzberg, 2006). Esses grupos se submetem a regras, normas e padrões de comportamento gerais (contexto histórico-institucional), porém a partir de interpretações particulares, condicionadas por subculturas específicas com dinâmicas e padrões sociais próprios de atuação, gerando contradições no interior do sistema.

O objetivo do artigo é apresentar a proposta de um esquema analítico sobre processo estratégico. Está fundamentado em três dimensões (agentes, contexto e sistemas organizacionais) interdependentes quando da ação estratégica, sendo realizada uma análise não determinística de eventos que constituem um dado episódio, no sentido de permitir ao pesquisador realizar interpretações.

O esquema deve ser capaz de orientar-se nas respostas de algumas questões presentes no campo de estudos sobre processo e prática da estratégia, como: quem são os agentes estratégicos; como eles tomam as decisões que podem levar às ações; de que forma essas ações se formam; como a combinação entre agentes, contexto e sistemas organizacionais mobilizam, potencializam ou restringem 
essas ações; que motivações e interesses ficam demonstrados pelos agentes; que jogos políticos ficam evidentes; quais as práticas reconhecidas nas ações estudadas, ou seja, como são formuladas e implementadas as estratégias.

A proposta foi elaborada a partir de fundamentação teórica e conjuntamente construída, aplicada e validada quando do episódio da criação e implantação do Projeto Pedagógico Institucional (PPI) da Escola de Artes, Ciências e Comunicação (Each) da Universidade de São Paulo (USP), por meio de uma pesquisa qualitativa, utilizando a abordagem de estudo de caso. Este artigo apresenta o processo de elaboração do esquema.

Sua estrutura é assim definida. Após esta introdução, de forma resumida, são apresentados os fundamentos da teoria da estruturação de Giddens (2003) e do modelo de transformação social de Sztompka (2005), que subsidiaram os principais elementos da proposta, e alguns aspectos sobre estratégia como processo e como prática. As seções seguintes destacam a metodologia, o processo de construção, a identificação e conceituação das principais dimensões, a dinâmica de funcionamento, a visão geral e uma proposta de operacionalização do esquema em pesquisas organizacionais. Nas considerações finais, apresentam-se as conclusões e pontuam-se acertos, limitações e sugestões de desenvolvimentos futuros da pesquisa.

\section{REFERENCIAL TEÓRICO}

Esta seção é constituída pela apresentação dos principais conceitos das teorias de estruturação de Giddens (2003) e da transformação social de Sztompka (2005). Em seguida, abordam-se aspectos da estratégia vista como processo e como prática. A revisão teórica empreendida concebe as teorias sociais e organizacionais destacadas como formas complementares, considerando suas diferenças, mas também seus pontos de interseção.

\subsection{TEORIA DA ESTRUTURAÇÃO}

Nas três últimas décadas do século passado, novos estudos na área sociológica procuraram enfrentar as dicotomias entre os conceitos de objetividade e subjetividade, determinismo e voluntarismo, e estrutura e ação. Um desses estudos resultou na teoria da estruturação. Desenvolvida por Anthony Giddens (2003), sociólogo inglês, busca a aproximação teórica e empírica da agência humana e das estruturas sociais.

Procurando se afastar da ortodoxia sociológica predominante no século XX e associando-se às contribuições inovadoras para a teoria social, Giddens (2003) 
destaca três temas comuns em torno dos quais as inovações nessa área estão sendo desenvolvidas. Primeiramente, a ênfase no caráter ativo e reflexivo da conduta humana, uma resposta às teses que enxergam o comportamento humano como resultado de forças que os atores não controlam, nem compreendem. Segundo, é atribuído um papel fundamental à linguagem e às faculdades cognitivas na explicação da vida social. Terceiro, um aumento no distanciamento entre as ciências naturais e as sociais, e de suas bases epistemológicas.

A dualidade da estrutura é o conceito central em sua teoria. Em resumo, as estruturas configuram a ação das pessoas, mas é também essa mesma prática que constitui e reproduz as estruturas, sendo estas meio e resultado da conduta recursivamente organizada. Como afirma Giddens (2003), as propriedades da estrutura não existem fora da ação, mas fazem parte de sua produção e reprodução. Nesse sentido, agência e estrutura, no lugar de dicotômicas, constituem-se uma à outra (Sewell, I992), noção que procura desfazer a dicotomia macro e micro presente na análise social.

No caso em estudo, observou-se que os agentes estavam submetidos a duas forças estruturais: o projeto estratégico da Each e as regras do ambiente institucional de uma universidade pública. As ações empreendidas pelos grupos de agentes ora eram guiadas pelas forças institucionais, ora pelos princípios estratégicos estabelecidos no projeto, dinamicidade que constituiu a própria implementação da estratégia.

Deve-se considerar, na análise dessa dinâmica, que as estruturas são ativadas pelo que Giddens (2003) denomina de "cognoscitividade" dos agentes humanos - o que os agentes sabem acerca das razões por que atuam e como atuam -, e os agentes agem pondo em prática necessariamente essa estrutura de conhecimento. Essa perspectiva da ação humana não apenas como uma reação aos determinismos estruturais permite visualizar um espaço de criatividade e inovação a partir das estruturas de conhecimento e capacidades acumuladas pelos agentes no tempo e no espaço. Dependendo do grau de poder de cada agente ou grupo de agentes, de sua capacidade de influenciar outros grupos sociais, sua ação pode ter como consequência a transformação da própria estrutura que permitiu que ele agisse inicialmente (Sewell, I992), caracterizando um processo de mudança contínuo, fundamentado na estrutura e na ação.

Compreender o processo de estruturação implica reconhecer momentos de equilíbrio provisório e dinâmico, de homogeneidade e heterogeneidade, e de recursividade entre estrutura e agência, exigindo novos métodos de pesquisa. Ou seja, pensar a ação humana nas organizações como construção ou fenômeno social envolve a análise conjunta da própria ação, bem como os efeitos de determinadas propriedades estruturais sobre essa ação, seja restringindo-a e/ou facilitando-a (Giddens, 2003). 
Deve ser destacado o caráter processual do termo estruturação, em oposição à ideia estática de estrutura, mais comum na teoria organizacional. De acordo com Giddens (2003), estrutura possui um conceito particular que está relacionado com o conjunto de regras e recursos implicados recursivamente na reprodução social. As regras representam convenções sociais em que o seu conhecimento, pelos atores, inclui também o conhecimento dos contextos nos quais se aplicam, constituindo-se como guias de orientação para a conduta humana. Os recursos referem-se às capacidades (inclusive organizacionais) e à disposição dos atores para fazer as coisas acontecerem.

As regras não podem ser vistas como prescrições formalizadas, como quando são relacionadas a jogos. Segundo Giddens (2003), na reprodução dos sistemas sociais, mesmo as regras que são codificadas como leis estão sujeitas a uma diversidade muito maior de contestações do que as regras dos jogos. Para isso, contribuem os recursos que os agentes possuem ou mobilizam, sejam de conhecimento ou de poder, e que implicam respostas diferenciadas e a incorporação ou não de novas práticas sociais. Regras e recursos atuam de forma interdependente.

Convém agora esclarecer brevemente os conceitos de intencionalidade, consequências e evento, poder e contexto, fundamentais para a compreensão da teoria da estruturação e do próprio esquema analítico proposto.

Para caracterizar a agência, tem-se como premissa que a rotina da vida cotidiana ocorre como um fluxo de ação intencional, entretanto os atos têm consequências impremeditadas. Giddens (2003, p. I2) define uma ação intencional como: "o que caracteriza um ato que seu perpetrador sabe, ou acredita, que terá uma determinada qualidade ou desfecho e no qual esse conhecimento é utilizado pelo autor para obter essa qualidade ou desfecho". Para o autor, nem tudo o que é feito está relacionado com intencionalidade. Completando essa linha de raciocínio, as consequências do que os atores fazem, intencionalmente ou não, "são eventos que não teriam acontecido se eles tivessem se comportado de modo diferente, mas cuja realização não está ao alcance do poder dos agentes (independentemente de quais eram suas intenções)" (Giddens, 2003, p. I2).

Esses dois conceitos (evento e consequência) são centrais para o esquema analítico proposto. Uma das conclusões a que se chega sobre o efeito da complexidade no processo estratégico é o fato de este ser constituído por diversos eventos que ocorrem em tempo e espaço diferenciados. Não há como prever as consequências desses eventos. De forma retrospectiva, talvez seja possível certo ordenamento em torno de um projeto, caso determinado evento conquiste legitimidade entre os atores. No caso em estudo, o evento de elaboração do projeto estratégico foi uma composição de intenções dos gestores da USP, de comunidades da zona leste de São Paulo e do governador do Estado. 
Para Giddens (2003), a relação entre agência e poder é intrínseca. Ou seja, o poder não é um recurso a serviço do agente, mas algo que ele possui para poder atuar, para ser capaz de intervir no mundo. Poder, numa perspectiva da dualidade da estrutura, pressupõe relações pautadas em autonomia relativa e na dependência entre atores ou coletividades em contextos de interação social. Mesmo nos sistemas hierarquizados, sempre há recursos disponíveis para os atores dos diversos níveis influenciarem-se em suas atividades.

Esses conceitos elencados só podem ser investigados a partir das contextualidades de interação. Para contextualizar, o autor desenvolve os conceitos de episódio e conjuntura. Caracterizar um aspecto da vida social como episódio "é vê-lo como um certo número de atos ou eventos com um começo e um fim especificáveis, envolvendo assim uma determinada sequência” (Giddens, 2003, p. 287). Tratar algo como episódio significa "penetrar analiticamente na 'História', ou seja, identificar certos elementos como marcando a abertura de uma sequência de mudança e descrever essa sequência como um processo de transmutação institucional" (Giddens, 2003, p. 288). Significa estabelecer um recorte temporal e espacial, essencial para a pesquisa em processo estratégico. Por exemplo, o episódio de criação da Each foi constituído por eventos como a elaboração do projeto estratégico, a definição dos projetos pedagógicos dos cursos, a criação do primeiro curso de mestrado e o desenvolvimento da metodologia pedagógica.

Deve-se ressaltar que o autor analisa mudança em larga escala, ou seja, no nível social maior, e que sua teoria deve ser transposta para um nível mais próximo do organizacional se aplicada na análise de organizações, tarefa que autores como Pettigrew (1987), por primeiro, em uma perspectiva processual, e Jarzabkowski e Felton (2006) - pesquisadores da abordagem de estratégia como prática -, em seguida, procuraram empreender.

O autor conceitua conjuntura como a interação de influências que, num determinado tempo e lugar, são relevantes para um dado episódio. Salienta que a interpretação dessas influências a partir da cognoscitividade humana potencializa a mudança social. A criação da Each e o seu desenvolvimento dependeram da interpretação de aspectos conjunturais pelos agentes em ação, cuja análise permitirá uma melhor compreensão de como ocorreu o processo.

Ressalte-se que a fundamentação teórica da teoria da estruturação não deverá restringir a elaboração do esquema analítico aos seus pressupostos, em razão, primeiramente, da abrangência da teoria, o que impede, em função de espaço e foco, maior detalhamento dos outros conceitos que a constitui. Segundo, há necessidade de aproximá-la da teoria das organizações e dos processos organizacionais, sendo esse, como destacado, um intento ainda em construção, para o qual esta pesquisa pretende colaborar. 
Convém ainda salientar que a teoria da estruturação tem merecido críticas de autores como Archer (1982) justamente em uma de suas teses principais, a da dualidade da estrutura. Archer (1982), em seu o realismo social, critica o fato de Giddens (2003) ter promovido uma espécie de fusão entre estrutura e ação. Afirma que a estrutura social é tão real como as estruturas físicas não pelo fato de a podermos percepcionar, mas porque possui propriedades causais, defendendo no lugar da dualidade conceitual o dualismo analítico (Oliveira, 20II). Ao mesmo tempo, destaca que, para compreender a dialética estrutura-ação, há necessidade de situá-la no tempo histórico.

Como causalidade e processo são essenciais para o entendimento do processo estratégico e, ao mesmo tempo, a experiência empírica empreendida apresentava de forma nítida a separação entre as propriedades emergentes da estrutura e as propriedades emergentes da agência, houve, no curso da elaboração do esquema analítico, a necessidade de buscar uma teoria capaz de contemplar essas dimensões.

Uma complementação à teoria de Giddens (2003) nesses aspectos pode ser encontrada nos estudos sobre transformação social de Piotr Sztompka (2005), desenvolvidos no livro A sociologia da mudança social, em especial nos capítulos XIII a XV.

\subsection{MODELO DE TRANSFORMAÇÃO SOCIAL DE PIOTR SZTOMPKA}

$\mathrm{Na}$ tentativa de sintetizar e aperfeiçoar as principais ideias das teorias da agência e da moderna sociologia histórica, Sztompka (2005) constrói um modelo que visa apreender a constituição e o funcionamento dos processos de transformação social.

O autor distingue dois níveis de realidade social: o das individualidades e o das totalidades. O primeiro é constituído de pessoas, como indivíduos ou como membros de coletividades concretas (grupos, associações, comunidades etc.). O segundo é constituído de totalidades sociais abstratas de tipo supraindividual que representam a realidade social sui generis (sociedades, civilizações, sistemas sociais, incluindo as organizações etc.).

Acrescenta uma segunda distinção, relativa aos dois modos de existência da realidade social: o das potencialidades e o das realidades. O primeiro refere-se a tendências inerentes, germes ou sementes do futuro, capacidades, aptidões, poderes etc. O segundo concerne a processos, transformações, desenvolvimento, conduta, atividades. O autor relaciona esses elementos em uma estrutura quádrupla de modo vertical e horizontal, conforme demonstrado no Quadro I. 
QUADRO I

MODELO SZTOMPKA (PARTE I)

\begin{tabular}{lcc}
\hline & POTENCIALIDADE & REALIDADE \\
\hline TOTALIDADE & Estrutura & Operação \\
INDIVIDUALIDADE & Agente & Ação \\
\hline
\end{tabular}

Fonte: Sztompka (2005).

Na dimensão vertical, o modelo de Sztompka (2005) postula as relações complementares de emergência e autonomia. As estruturas são consideradas emergentes em relação aos agentes: ainda que os englobem, elas possuem propriedades e regularidades específicas. São redes interagentes, não redutíveis à soma deles. Mas os agentes também não são redutíveis à sua localização estrutural; eles possuem certo grau de autonomia, integridade e liberdade relativa para escolher e decidir. São entidades autossuficientes, com propriedades e regularidades específicas, e não meros pontos nodais das estruturas.

A relação vertical entre operação e ação é descrita de forma similar à anterior. A operação das estruturas - funcionamento da sociedade e das organizações deve ser tratada como emergente em relação às ações executadas pelos agentes. Ainda que as ações constituam, em última instância, a substância da operação da sociedade ou da organização, não são a ela redutíveis; ao combinar diversas ações inter-relacionadas, a operação adquire o seu próprio momentum, padrão ou lógica sequencial específica. Ela é mais do que a soma das ações.

A relação horizontal entre as dimensões do quadro também pode ser analisada. Entre agentes e ações, o conceito de mobilização sintetiza seu funcionamento. Os agentes mobilizam suas capacidades, aptidões, necessidades, atitudes e disposições potenciais, que correspondem às suas caracterizações, ao praticarem ações de todo tipo.

No nível superior, entre as estruturas e seu funcionamento (operação), ela será captada por meio do conceito de desdobramento. Segundo Sztompka (2005, p. 366), "as estruturas se desdobram em operações, descarregando, em seu funcionamento, as suas potencialidades, tendências e disposições inerentes".

Desenvolvendo um pouco mais o seu modelo, o autor insere um nível intermediário. O nível da agência (como potencialidade) e da práxis (como realidade). Para Sztompka (2005, p. 367), "é aqui, na interface, entre estruturas e agentes, operações e ações, que o enigma da transformação social deve ser investigado", é aqui que ocorre a trama social motriz-estrutural. Esta aparece com "combinações diversas, misturas diversas dos ingredientes propulsores e estruturais que constituem os eventos sociais" (Sztompka, 2005, p. 368). 
Para o autor, a matéria definitiva, os componentes reais de que é feita a sociedade, são os eventos, nem atos individuais nem "fatos sociais", mas sua fusão íntima, concreta. A realidade organizacional ocorre nessa fusão - nos eventos -, em que combinações diversas de estruturas e agentes se manifestam. Pode-se, de alguma maneira, afirmar que nos eventos ocorrem as ações estratégicas, materialização da própria estratégia. Quando se estudam os eventos como um núcleo motriz-estrutural, portanto, a interseção de ação e estrutura, está se estudando o núcleo do processo estratégico.

Práxis pode ser definida como o ponto de confluência entre a operação e a ação: síntese dialética do que está acontecendo em uma sociedade e do que as pessoas estão fazendo. Agência é potencialidade, ou seja, um conjunto de aptidões, disposições, tendências inerentes à trama social, que propicia o seu aparecimento, resume certas propriedades da trama social: "É onde se encontram as estruturas (capacidade de operação) e os agentes (capacidade de ação); é um conjunto sintético, uma fusão de circunstâncias estruturais e capacidade propulsora" (Sztompka, 2005, p. 370).

Agência e práxis no modelo de Sztompka (2005) se ligam horizontalmente pelo processo de "eventuação". A Figura I sintetiza os elementos da segunda etapa do modelo e apresenta as suas relações.

\section{Figura I}

MODELO SZTOMPKA (PARTE 2)

\begin{tabular}{lcc}
\hline & POTENCIALIDADE & REALIDADE \\
\hline Totalidade & Estruturas & Operação \\
Realidade & Agência $\ldots \ldots+\cdots$ & Ação \\
\hline
\end{tabular}

Fonte: Sztompka (2005).

O trabalho de Sztompka (2005) é amplo e complexo, e foge ao objetivo deste artigo um maior detalhamento. Porém, dois últimos elementos de seu modelo são essenciais para fundamentar o esquema analítico a ser proposto: tempo e história.

Para o autor, quando se fala do desdobramento das estruturas em operação, ou da mobilização dos agentes na ação, ou ainda da eventuação da agência na 
práxis, "assumimos claramente uma dimensão temporal; todos esses processos só podem ocorrer no tempo" (Sztompka, 2005, p. 380).

Considerando essa afirmação, um evento é consequência de eventos anteriores e fundamento para eventos futuros. Todos os elementos do modelo sofrem impactos a partir desse processo. Isso pode ser descrito assim:

Os eventos sociais, que fundem a operação estrutural e a ação propulsora (ou simplesmente práxis) em um dado instante de tempo, influenciam tanto as estruturas (modificando ou conformando novas redes relacionais) quanto os agentes (modificando ou conformando suas capacidades imanentes) em um momento posterior. Como resultado, uma agência nova ou modificada aparece. O potencial da sociedade para a práxis foi alterado (Sztompka, 2005, p. 382).

Ao se analisar uma sequência de eventos, é essencial a referência ao curso da história de uma determinada organização, os momentos que marcaram a mudança nas potencialidades e realidades de uma dada organização.

A partir do exposto, é possível assumir para a construção do esquema que as operações (Sztompka) são representadas, no nível organizacional, pelos sistemas (processos) organizacionais, os elementos da organização que potencializam a intermediação entre contexto histórico, social e cultural (totalidade) e agentes (individualidades e grupos).

Em seguida, de forma sucinta, as abordagens de estratégia como processo e como prática são apresentadas.

\subsection{ESTRATÉGIA COMO PROCESSO E COMO PRÁTICA}

O processo estratégico define o modo como as estratégias de uma organização são elaboradas e implementadas. Em sentido similar ao explorado neste trabalho,

[...] busca-se desvendar de que modo são tomadas as decisões e ações que dizem respeito à execução estratégica, incluindo assimilação e reação a interferências externas. Além disso, buscam-se explicações das consequências geradas a partir de padrões decisórios e/ou de ações tomadas no decorrer do tempo (Bulgacov et al., 2007, p. 85).

Entre suas características, estão a dinamicidade e multiplicidade de níveis em que as ações ocorrem, gerando múltiplos níveis de análise, ou seja, é um fenômeno que abrange mais do que simplesmente os níveis hierárquicos 
formais da organização: "Inclui interações entre os indivíduos, entre grupos, entre grupos e estruturas, entre grupos e rotinas, entre organizações e setores industriais e entre setores e políticas econômicas" (Bulgacov et al., 2007, p. 86).

Apesar da diversidade de autores que podem ser situados nessa abordagem, para o desenvolvimento do esquema analítico, foram fundamentais as teses de Van de Ven (I992) e Pettigrew (I992). Ambos definem processo como uma sequência de eventos individuais e coletivos, ações e atividades que se desdobram ao longo do tempo em um determinado contexto. Para Pettigrew (I992), autor influenciado por Giddens, é possível, no desenrolar desses eventos, captar como a estratégia ocorre de fato.

Uma das teses defendidas pelos autores da estratégia como processo refere-se ao modo como é formulada. Consideram que uma estratégia tanto pode ser formulada de forma premeditada e enunciada em plano estratégico a priori (Ansoff, I965), como emergir como padrão historicamente contingente de ações interdependentes que, organizadas retroativamente sob o ponto de vista do presente, são enunciadas posteriormente (Mintzberg, I978). Observe-se que formulação, formação e elaboração nesta última abordagem podem ser utilizadas como sinônimos.

Deve-se atentar para não desconsiderar o conteúdo estratégico quando dos estudos sobre processo (Chakravarthy \& Doz, I992). A estratégia em análise é o projeto pedagógico da nova unidade universitária. É composto por concepção de educação, princípios pedagógicos, metodologias de aprendizagem e ações relacionadas com a escolha e implantação de cursos de graduação, extensão e pós-graduação.

$\mathrm{Na}$ abordagem da estratégia como prática, os agentes e os sistemas organizacionais são analisados com maior proximidade. Os autores que a utilizam fazem os seguintes questionamentos:

a) O que acontece quando as estratégias são colocadas em prática, e como os indivíduos, especialmente os gerentes, contribuem nesse processo? b) Como as organizações, com suas culturas sedimentadas e suas complexas estruturas, interagem com o processo e o influenciam? (Wilson \& Jarzabkowski, 2004, p. I2).

Os autores dessa abordagem foram buscar referências nas "teorias da prática" oriundas, principalmente, da sociologia, em autores como Giddens, Bourdieu e Sztompka, e da filosofia, principalmente em Heidegger e Wittgenstein, para entender a estratégia como uma prática social (Whittington, 2004).

A estratégia como prática lida com a questão da agência a partir de três dimensões analíticas: iterativa, projetiva e prática avaliativa (Emirbayer \& Mische, I998). A agência iterativa, segundo Wilson e Jarzabkowski (2004), tende a reproduzir a 
prática existente. Fundamenta-se no princípio da recursividade da teoria da estruturação, no qual os atores agem a partir da reconstrução de suas experiências do passado. Em um dos eventos analisados, a elaboração de um projeto de mestrado na nova unidade da USP, os agentes (em sua maioria, jovens doutores) buscam seguir as regras da pós-graduação brasileira no intuito de obter legitimidade perante seus pares, mesmo que isso implique ir de encontro ao projeto pedagógico em implantação.

A dimensão projetiva da agência envolve imaginações projetivas de futuro e retoma a imagem do estrategista como um visionário. Adota uma metáfora da escola de empreendedorismo utilizada por Mintzberg et al. (2000). De alguma forma, essa escola retoma uma ideia de estratégia formulada e centralizada no topo da escola clássica. Apresenta-se muito clara no caso analisado quando os gestores (reitor, pró-reitores, diretores) traçaram uma estratégia inovadora no ambiente conservador da USP.

A terceira dimensão, prática-avaliativa, percebida nos dois eventos analisados, é assim definida por Wilson e Jarzabkowski (2004, p. I5):

Mesmo quando os estrategistas projetam o futuro, não conseguem prever o resultado. Em vez disso, ao se mover na direção de suas projeções eles devem se basear nos recursos existentes, que provavelmente serão aqueles associados à agência iterativa, isto é, modelos disponíveis de se fazer estratégia. Esta dimensão da agência envolve, portanto, que atores reflitam e que sejam capazes de entender suas ações atuais dentro do contexto de ações passadas e de aspirações futuras, e que façam a mediação entre as duas coisas de forma a poder desafiar e transformar a prática existente.

Essas três práticas, porém, ocorrem por meio de uma ação coletiva, como um processo incremental que resulta de ajustes mútuos entre grupos de interesses múltiplos. Segundo Astley e Van de Ven (2007, p. I00), “embora os atores partidários persigam seus próprios interesses, eles o fazem, no entanto, dentro de limites, e devem negociar com os demais para encontrar concessões que sejam aceitáveis de um ponto de vista coletivo".

A metodologia é apresentada em seguida.

\section{METODOLOGIA}

A pesquisa pode ser caracterizada como qualitativa (do tipo fenomenológico), pois utiliza uma série de técnicas interpretativas que procuram "descrever, 
decodificar, traduzir e entender o significado de certos fenômenos que ocorreram com relativa naturalidade em uma organização" (Collis \& Hussey, 2005, p. I45). Pode também ser considerada uma pesquisa analítica com vistas à geração de um esquema de análise interpretativo.

Sua proposta, a elaboração de um esquema analítico sobre processo estratégico, foi desenvolvida por meio de um processo no qual teoria e prática se complementavam. Contribuíram no campo sociológico as teorias de Giddens (2003) e Sztompka (2005), e, no organizacional, as ideias de Pettigrew (1992) - quando afirma que o processo estratégico precisa ser estudado juntamente com o conteúdo e o contexto - e Van de Ven (I992), ao destacar a importância da análise histórica, da definição de uma teoria de processo e da interação do pesquisador com os participantes da pesquisa, e a necessidade de explicar o significado do processo estratégico, ou seja, definir a sua forma e por que ele ocorre.

A escolha do caso - a Escola de Artes, Ciências e Humanidades (EACH) - foi influenciada pelo fato de que o processo estratégico ainda estava em desenvolvimento. Dessa forma, foi possível realizar pesquisa documental e entrevistas para resgatar os eventos relevantes do processo e interpretar a percepção e os sentimentos dos atores. Também havia disposição e interesse dos gestores e professores da unidade em participar da pesquisa e contribuir para a compreensão do fenômeno analisado.

Ao longo de aproximadamente dois anos, o autor observou atividades e comportamentos, participou de eventos, conversou informalmente com 98 gestores, professores e alunos (cujo conteúdo foi registrado nas anotações de campo) e entrevistou em profundidade 24 pessoas, entre gestores e professores.

Os critérios para escolha dos sujeitos da pesquisa foram a participação destes nos eventos analisados, sendo a identificação obtida por meio do registro dos nomes nos documentos, e a indicação de pessoas com as quais o pesquisador manteve algum diálogo.

Fundamentado no referencial teórico e nas reflexões sobre um caso real, o esquema foi elaborado.

\section{A CONSTRUÇÃO DO ESQUEMA ANALÍTICO}

Quando se detalha o processo de elaboração do esquema, é possível realizar a seguinte síntese dos fundamentos teóricos. Realiza-se uma abordagem de prática social que estuda a construção social da realidade a partir da dualidade 
entre estrutura e ação. Busca-se apreender as contradições dialéticas geradas pela interação dos agentes, em eventos delimitados, imersos em uma realidade histórica, social e cultural que guia os seus processos interpretativos e é mediada por regras e recursos de uma organização específica, podendo resultar em mudanças organizacionais e sociais.

Comungando com Vasconcelos, Mascarenhas e Protil (2004), o objetivo é apreender as categorias sociais relevantes, reconstruir as experiências dos atores e os significados socialmente construídos, detectar as regularidades, para se chegar a uma interpretação possível sobre o fato estudado. A regularidade ocorre à medida que há compartilhamento de sentido (significado) entre agentes relativamente às estruturas e aos espaços de ação e recorrência de valores, crenças e interesses (motivações) entre esses mesmos agentes (Meirelles, 2003).

São as contradições e inconsistências entre os diversos grupos de uma organização que geram a dialética propulsora da práxis social, no espaço onde ocorre a ação estratégica e no qual o processo estratégico tem seu núcleo motriz. A estratégia desdobra-se em um conjunto de eventos que geram outros eventos que resultam em uma trajetória (Van de Ven \& Poole, r995) e que, retrospectivamente (Mintzberg \& Waters, I985), constituem um fenômeno específico de análise.

\subsection{DIMENSÕES, DINÂMICA E VISÃO GERAL}

O esquema possui três dimensões assim definidas: I. contexto histórico, social e cultural, 2. agentes e 3. sistemas organizacionais.

As organizações devem ser compreendidas dentro de um espaço social e de um tempo específicos, constituindo o que se denomina de contexto histórico, social e cultural. O histórico, o social e o cultural estão intrinsecamente ligados, pois não existem relações sociais entre os indivíduos e os grupos nem entre estes e os objetos sociais que se deem sem referência a um tempo e a um espaço (Freitas, 2007).

O contexto histórico, social e cultural está situado no nível das totalidades sociais abstratas de Sztompka (2005), representa a realidade social no passado e no presente, e sinaliza aspectos do futuro. É interpretado no esquema como constituído por estruturas externas, sendo formador/influenciador de estruturas internas à organização. Essas estruturas são representadas por regras normativas, culturais e simbólicas, normalmente conceituadas como institucionais. Contêm ao mesmo tempo elementos da história na qual uma organização foi se formando e que acabam por emergir quando dos processos de interpretação dos agentes envolvidos em uma dada ação estratégica. 
No campo subjetivo, são propriedades de um setor organizacional ou de uma organização, e não de indivíduos ou grupos localizados. Indicam formas de se comportar e de fazer as coisas para que sejam aceitas e legitimadas pela maioria.

No campo objetivo, o contexto se concretiza por meio de normas, leis e resoluções, mas também se encontra em discursos legitimados, ferramentas, modos de proceder ditos como certos situados no setor social em que a organização está inserida e que passam a constituir um sistema de crenças que pode de algum modo restringir, mas também potencializar as ações empreendidas pelos diversos grupos (Whittington, 2004).

Os fatos relacionados ao contexto devem ser demarcados no passado e no presente, porém, em razão da amplitude de eventos que constituem a história de um setor organizacional e de uma organização específica, há necessidade de limitar a análise. Quando da abordagem histórica, o que se busca, prioritariamente, são os eventos passados que implicaram mudanças ou que resultaram em regras e práticas institucionalizadas, como a proposta de criação de uma nova organização, uma reforma legal, mudanças nas políticas de governo ou, de forma mais localizada, na estrutura da organização e projetos de reorganização internos.

No tempo presente, percebe-se que um determinado evento emerge a partir de forças contextuais específicas. Não são aspectos gerais de um ambiente econômico ou social, mas fatos relevantes que, na interpretação dos agentes, participam diretamente no desenvolvimento de um determinado evento. Uma crise que desencadeia pressões sociais, uma oportunidade originada pela elaboração de um projeto inovador e a possibilidade de um grupo social fortalecer sua legitimidade são fatos que podem servir como exemplos.

A dimensão de sistemas organizacionais, que corresponde ao nível das estruturas (regras e recursos) internas à organização, é dividida no esquema em duas partes: I. as regras (estrutura organizacional, cultura organizacional, estruturas não formais e subculturas) e 2. os recursos (gestão de pessoas, gestão estratégica, liderança, jogos de poder, uso de tecnologia, processos decisórios, processos de influência e coordenação, por exemplo).

As regras possuem estabilidade maior, e os agentes devem procurar ajustar suas ações a elas. Essa estabilidade, porém, é relativa, em razão dos processos dialéticos existentes no interior da organização (Giddens, 2003; Sztompka, 2005). A estrutura e a cultura da organização consolidadas ou institucionalizadas são confrontadas a todo o momento por estruturas não formais e por culturas emergentes formadas a partir da constituição quase que permanente de grupos que acabam por constituir subculturas. 
Os recursos implicam processos, transformação, desenvolvimento, conduta e atividades que mesmo constituindo a estrutura organizacional estão mais próximos da interferência dos agentes (grupos) que os utilizam na modificação ou permanência das regras estruturais quando os mobilizam na ação.

Eles podem ser representados por processos decisórios, comportamento gerencial, liderança, comportamento administrativo, processo de influência e coordenação (Bastos, 2009), mas também por processos mais ordenados de gestão de pessoas, gestão estratégica e uso de tecnologia, conforme destacado anteriormente, que traduzem uma espécie de competência organizacional.

Os agentes - que correspondem ao nível das individualidades no modelo de Sztompka - é a dimensão constituída por indivíduos e membros de coletividades concretas (grupos, associações etc.). O plural do conceito significa que a abordagem do esquema se dá, predominantemente, no nível dos grupos ou dos agentes interligados.

No nível dos agentes, as ações têm por base suas ideias, pensamentos e crenças. Atuam a partir de sua cognoscitividade (Giddens, 2003) - saber jogar o jogo, usar o discurso, persuadir, ganhar apoios - quando motivados ou interessados por algo (definir uma identidade, encontrar um lugar, ser reconhecido). O que os diferenciam são suas capacidades ou recursos individuais (criatividade, inovação, experiência etc.).

Em função da dimensão organizacional analisada na pesquisa, o processo estratégico, os agentes são os que participam de uma ação estratégica numa posição de definir a sua direção. Normalmente, são os gestores de níveis superior e médio. Na universidade na qual o esquema foi aplicado, porém, diagnosticaram-se eventos coordenados diretamente por docentes, com pouca interferência dos gestores.

Há necessidade agora de integrar essas dimensões. O contexto histórico, social e cultural e as estruturas organizacionais de alguma forma restringem o espaço de interpretação e de ação dos agentes em uma situação específica capaz de gerar uma ação estratégica. Porém, ao mesmo tempo, os agentes não se limitam a responder às demandas contextuais e acatar as regras estruturais, possuindo diferentes graus de autonomia que podem se ampliar em determinados eventos quando, ao constituírem um grupo, adquirem mais poder e mobilizam recursos capazes de influenciar no desenvolvimento da organização (Johnson, Scholes, \& Whittington, 2007). 
A Figura 2 representa o ponto de interseção entre as dimensões do esquema.

FIGURA 2

\section{INTERSEÇÃO DAS DIMENSÕES DO ESQUEMA}

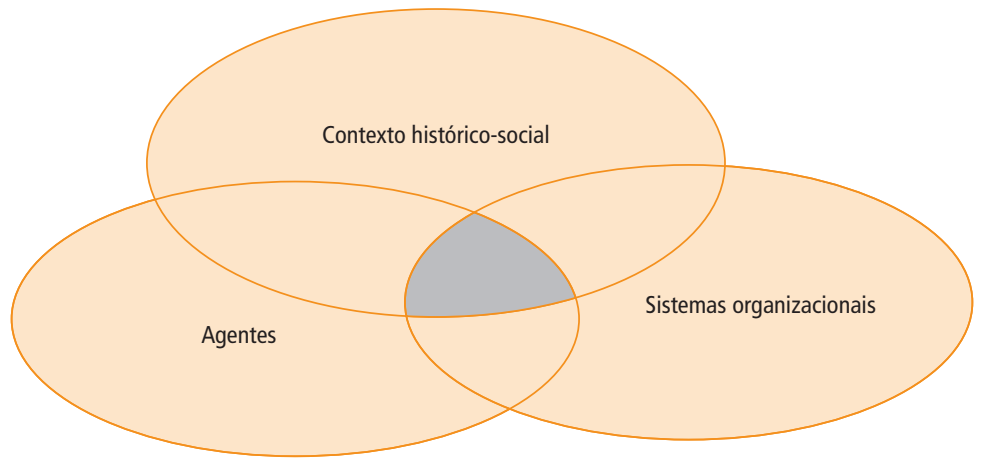

Fonte: Elaborada pelo autor.

Parte-se do princípio da formação de um núcleo motriz-estrutural (Sztompka, 2005) capaz de sintetizar a trama construída por experiências e relacionamentos que acontecem em contextos específicos, intermediados por estruturas organizacionais. Essa trama encontra a sua síntese nos eventos, componentes reais de como é feita a sociedade. Fazendo uma correlação com o foco do artigo, os eventos representam ações estratégicas constituintes de um determinado episódio em estudo, como, no caso, a criação e implantação de uma nova unidade universitária.

Para que um evento ocorra, não basta a interseção das dimensões, o núcleo precisa ser ativado, sendo necessário que os agentes queiram e possam atuar. Os agentes são sempre potencialidades que se mobilizam por meio da ação, no caso específico, da interação, uma ação produzida em conjunto, em que existem trocas e influências recíprocas, e por meio da qual vão se consolidando formas de interpretação da realidade comuns (intersubjetividade) e mecanismos próprios de utilização dos recursos estruturais da organização.

Quando o núcleo motriz é acionado, ocorre a integração das dimensões do esquema em torno de um núcleo que resulta em "práxis". Práxis é o resultado da síntese dialética da ação empreendida pelos agentes ao mobilizarem regras e recursos organizacionais, a partir da interpretação do contexto histórico-social. É um conjunto de atividades que efetuam transformações e produções, é uma qualidade nova emergente, não redutível isoladamente a nenhuma das três dimensões. Ela é fruto de uma conjuntura.

Essa conjuntura representa a combinação da capacidade de os sistemas organizacionais operarem, das habilidades, dos conhecimentos e das atitudes 
dos agentes envolvidos, e do contexto mais específico em que se desenvolve um evento. Nenhuma das três dimensões opera isoladamente, são complementares, operam por meio de uma dialética, e o resultado é fruto de combinações que não podem ser previstas a priori.

Deve-se ressaltar que o espaço criado pela interação não é apenas construído a partir da utilização de técnicas semelhantes de trabalho ou de mecanismos operacionais legitimados institucionalmente. É também, e principalmente, um espaço sociocêntrico, ou seja, quando sua construção se dá a partir do grupo e prevalece a oposição nós/os outros.

Nesse espaço em que os indivíduos se encontram, ocorre um compartilhamento intersubjetivo de ideias, valores e crenças e formas de comportamento. Ocorre também uma interação recursiva entre o domínio da ação dos grupos, o contexto e a organização. Nesse momento, mesmo sendo essas dimensões objetivamente diferenciadas, congregam-se em torno de um núcleo de ação estratégica, a qual somente pode ser compreendida a partir da análise das diversas combinações entre essas dimensões que surgem no decorrer dessa ação.

O processo de "eventuação" (ação estratégica) só pode ocorrer no tempo. Sztompka (2005) diferencia dois tipos de tempo: externo (de transformação) e interno (de funcionamento). O modelo trabalha com o tempo de funcionamento de um fenômeno, no qual a mudança possui um ritmo próprio conduzido pelos agentes. O tempo de transformação, no qual as mudanças sociais são mais radicais e atingem as estruturas sociais (instituições), também pode ser analisado por meio do esquema, mas implicará metodologia de pesquisa longitudinal.

A Figura 3 demonstra todos os elementos que compõem o núcleo motriz-estrutural do esquema e sua dinâmica.

\section{FIGURA 3}

\section{"EVENTUAÇÃO"/AÇÃO ESTRATÉGICA}

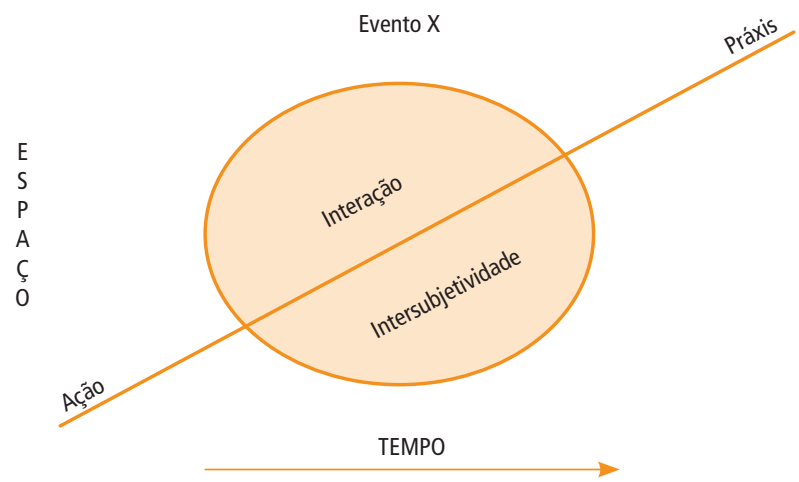

Fonte: Elaborada pelo autor. 
A partir da apresentação desse núcleo motriz da ação estratégica, é possível agora compor, utilizando a fundamentação teórica apresentada, uma visão geral das etapas do esquema proposto para a análise de um processo estratégico em uma universidade, conforme a Figura 4.

\section{FigurA 4}

\section{ESQUEMA ANALÍTICO: VISÃO GERAL}

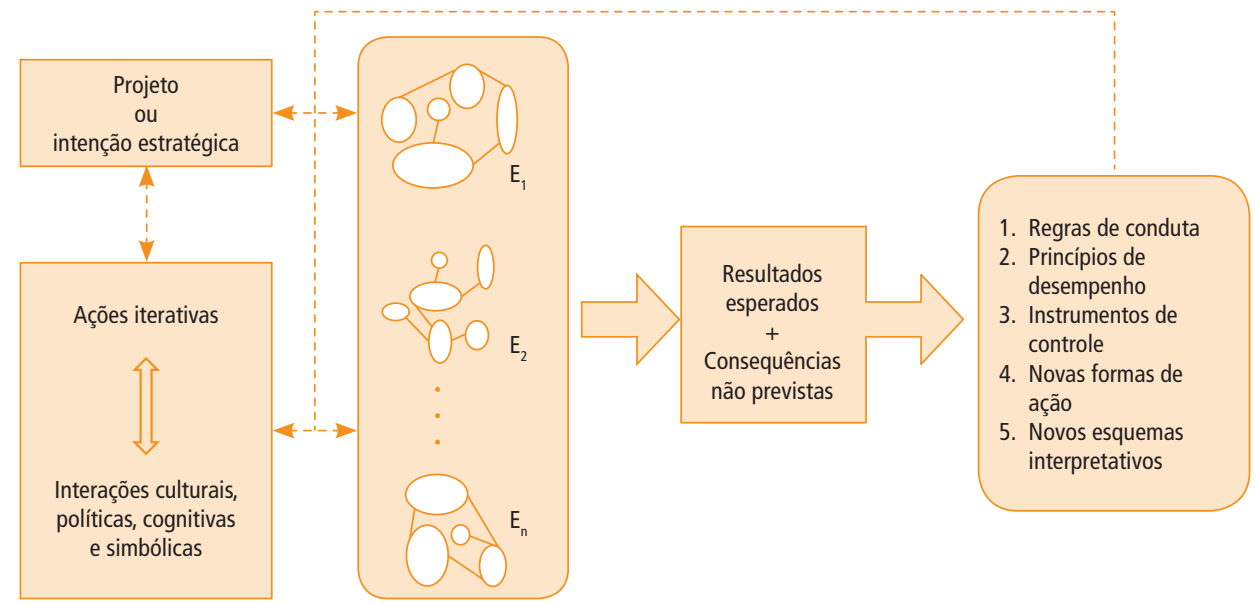

Fonte: Elaborada pelo autor.

Um episódio pode surgir de um projeto com objetivos e metas detalhados ou, pelo menos, de intenções estratégicas declaradas em princípios e diretrizes. Esse projeto mobiliza agentes em interações culturais, políticas, cognitivas e simbólicas. Essa mobilização gera várias ações estratégicas ou eventos (representados apenas visualmente pelos conjuntos de círculos) que, de forma em parte planejada, parte não, configuram uma dada trajetória para o processo estratégico.

Ao longo dessa trajetória, são alcançados resultados/efeitos esperados, mas também não esperados que podem implicar mudanças localizadas ou abrangentes, evidenciadas em uma universidade, por exemplo, em regras de conduta (mudança de comportamento dos agentes), em princípios de desempenho (novos critérios de avaliação), em instrumentos de acompanhamento e controle, em novas formas de ação e no surgimento, no longo prazo, de novos valores e crenças assumidos pelos grupos de uma organização.

É importante salientar que a visão linear do esquema é apenas didática, pois formulação e implementação de uma ação estratégica ocorrem muitas vezes de forma indissociada, sendo que, algumas vezes, uma determinada ação somente 
pode ser analisada como constituinte de uma estratégia retrospectivamente. Portanto, o início de um processo estratégico pode ocorrer em qualquer parte do modelo. Dessa forma, o processo se autoalimenta, e um determinado evento possui a capacidade de alterar um projeto ou uma intenção inicial.

Em seguida, é apresentada a proposta de operacionalização do esquema em pesquisas.

\subsection{OPERACIONALIZAÇÃO DO ESQUEMA}

Um esquema analítico é uma estrutura composta de dimensões entre as quais existem relações. Cada dimensão comporta variáveis que ainda não estão particularizadas para uma utilização em um contexto específico. Em se tratando de abordagem metodológica, essas variáveis serão especificadas a partir da percepção dos agentes sobre suas próprias ações, interpretadas pelo pesquisador com base em entrevistas, documentos e observações.

Para obter essa interpretação, uma entrevista semiestruturada deve ser elaborada com o propósito de obter a percepção dos agentes e os significados para eles de suas ações em um determinado evento, além dos fatores mediadores, sempre procurando relacionar essa interpretação ao fenômeno central em estudo.

Como orientação para elaboração das questões das entrevistas e análise dos dados obtidos, é sugerida a utilização de uma codificação baseada em conceitos. A partir da pesquisa empreendida e da construção teórica elaborada, chegou-se aos construtos da pesquisa e às suas definições conceituais e operacionais, demonstrados no Quadro 2.

\section{QUADRO 2}

PRINCIPAIS CONSTRUTOS DO ESQUEMA

NA OPERACIONALIZAÇÃO DE PESQUISAS

\begin{tabular}{|c|c|c|}
\hline CONSTRUTOS & DEFINIÇÃO CONCEITUAL & DEFINIÇÃO OPERACIONAL \\
\hline $\begin{array}{l}\text { Contexto } \\
\text { histórico, social } \\
\text { e cultural }\end{array}$ & $\begin{array}{l}\text { É a trajetória histórica de uma } \\
\text { organização específica que } \\
\text { pode ter influenciado um } \\
\text { determinado evento. Refere-se } \\
\text { também a aspectos sociais - } \\
\text { como questões de legitimidade } \\
\text { no setor que impactam } \\
\text { determinada organização - que } \\
\text { são percebidos pelos agentes } \\
\text { como influentes. }\end{array}$ & $\begin{array}{l}\text { Leitura de documentos, realização } \\
\text { de entrevistas com agentes e } \\
\text { observação de aspectos da cultura } \\
\text { organizacional que objetivam, por } \\
\text { um lado, reconstruir a trajetória da } \\
\text { organização a partir dos principais } \\
\text { marcos institucionais e, por outro, a } \\
\text { identificação dos fatores influentes } \\
\text { do presente. }\end{array}$ \\
\hline
\end{tabular}

(continua) 
QUADRO 2 (CONTINUAÇÃO)

PRINCIPAIS CONSTRUTOS DO ESQUEMA

NA OPERACIONALIZAÇÃO DE PESQUISAS

\begin{tabular}{|c|c|c|}
\hline CONSTRUTOS & DEFINIÇÃO CONCEITUAL & DEFINIÇÃO OPERACIONAL \\
\hline $\begin{array}{l}\text { Sistemas } \\
\text { organizacionais }\end{array}$ & $\begin{array}{l}\text { São as regras e os recursos da } \\
\text { organização. Entre as regras, } \\
\text { destacam-se a estrutura } \\
\text { de poder e a cultura da } \\
\text { organização. Entre os recursos, } \\
\text { estão a gestão estratégica, a } \\
\text { gestão de pessoas, a liderança, } \\
\text { os jogos de poder, o uso de } \\
\text { tecnologia etc. }\end{array}$ & $\begin{array}{l}\text { A partir da realização de entrevistas } \\
\text { com os agentes e da pesquisa } \\
\text { documental, identificar ou intuir } \\
\text { os sistemas da organização que } \\
\text { influenciam ou são mobilizados por } \\
\text { estes em um determinado evento, de } \\
\text { modo a possibilitar a sua emergência. }\end{array}$ \\
\hline Agentes & $\begin{array}{l}\text { Os indivíduos que participam } \\
\text { diretamente de um determinado } \\
\text { evento e que possuem poder } \\
\text { para influenciá-lo e modificá-lo. }\end{array}$ & $\begin{array}{l}\text { Caracterizar o perfil dos indivíduos } \\
\text { de um determinado grupo a partir } \\
\text { de relatos de suas participações em } \\
\text { determinado evento e dos relatos } \\
\text { de história de vida. De forma mais } \\
\text { específica: buscar identificar se são } \\
\text { criativos e orientados para realizações } \\
\text { ou passivos, conservadores e tendentes } \\
\text { à conciliação. Salientar capacidades e } \\
\text { competências individuais. }\end{array}$ \\
\hline Ação & $\begin{array}{l}\text { Trata-se de atividades } \\
\text { desenvolvidas pelos agentes } \\
\text { de forma rotineira. }\end{array}$ & $\begin{array}{l}\text { A partir dos relatos de participação dos } \\
\text { agentes em determinado evento e da } \\
\text { observação na organização, identificar } \\
\text { rotinas, práticas e mecanismos técnicos } \\
\text { mobilizados pelos atores em suas } \\
\text { interações e discursos do dia a dia. }\end{array}$ \\
\hline Interação & $\begin{array}{l}\text { Espaço e tempo em que } \\
\text { ocorrem os encontros face a } \\
\text { face dos indivíduos, trocam } \\
\text { informações e constroem o } \\
\text { sentido de suas ações. Formas } \\
\text { de relacionamento; como ocorre } \\
\text { a aproximação entre os agentes; } \\
\text { formas de comunicação; } \\
\text { frequência em que ocorre. }\end{array}$ & $\begin{array}{l}\text { Caracterizar os espaços em que } \\
\text { ocorrem as interações face a face } \\
\text { dos agentes participantes de um } \\
\text { evento. Por meio das entrevistas e } \\
\text { da observação, identificar aspectos } \\
\text { comportamentais dos agentes nos } \\
\text { grupos (liberdade de se expressar, } \\
\text { possibilidade de correr riscos) e os } \\
\text { aspectos físicos desses espaços. }\end{array}$ \\
\hline
\end{tabular}

(continua) 
QUADRO 2 (CONCLUSÃO)

PRINCIPAIS CONSTRUTOS DO ESQUEMA

NA OPERACIONALIZAÇÃO DE PESQUISAS

\begin{tabular}{|c|c|c|}
\hline CONSTRUTOS & DEFINIÇÃO CONCEITUAL & DEFINIÇÃO OPERACIONAL \\
\hline Intersubjetividade & $\begin{array}{l}\text { Ideias, valores e crenças } \\
\text { construídos na experiência } \\
\text { cotidiana e subjetiva pelos } \\
\text { indivíduos durante os processos } \\
\text { de interação. O que cria sentido. }\end{array}$ & $\begin{array}{l}\text { Por meio das entrevistas com os } \\
\text { agentes de determinado evento, } \\
\text { é possível interpretar quais normas, } \\
\text { valores e regras orientam as ações; } \\
\text { quais sentimentos/motivações/ } \\
\text { interesses os agentes expressam } \\
\text { de forma comum. }\end{array}$ \\
\hline Núcleo motriz & $\begin{array}{l}\text { Local onde as três dimensões } \\
\text { principais do esquema } \\
\text { se encontram e, por } \\
\text { meio da interação e da } \\
\text { intersubjetividade, constroem } \\
\text { e dão sentido às ações que } \\
\text { resultam em práxis. }\end{array}$ & $\begin{array}{l}\text { Interpretação por parte do } \\
\text { pesquisador, fundamentado nas } \\
\text { entrevistas e nos dados documentais, } \\
\text { das combinações entre as três } \\
\text { dimensões que constituem uma dada } \\
\text { conjuntura. Permite a reflexão sobre } \\
\text { as condições de emergência de certa } \\
\text { ação estratégica. }\end{array}$ \\
\hline Práxis & $\begin{array}{l}\text { Forma de agir resultante de } \\
\text { uma determinada conjuntura } \\
\text { constituída por características } \\
\text { de um determinado contexto, } \\
\text { sistemas organizacionais e } \\
\text { agentes em uma perspectiva } \\
\text { dialética. É o que constitui uma } \\
\text { ação estratégica ou um evento. }\end{array}$ & $\begin{array}{l}\text { Realização de entrevistas com } \\
\text { agentes participantes de um } \\
\text { processo. Interpretação por parte } \\
\text { do pesquisador dos efeitos gerados } \\
\text { com a implementação de uma ação } \\
\text { estratégica. }\end{array}$ \\
\hline
\end{tabular}

Fonte: Elaborado pelo autor.

É apresentado, na sequência, o detalhamento das etapas sugeridas para a operacionalização do esquema.

\subsubsection{Primeiro passo: definição do evento}

A definição do evento é de livre escolha do pesquisador, mas deve seguir, quando possível, as proposições de Van de Ven (1992) quanto ao fato de o evento ainda estar em desenvolvimento. A intuição do pesquisador participa ativamente na avaliação do grau de influência de determinado evento no processo como um 
todo. Evidentemente, a escolha também estará condicionada ao interesse e à disponibilidade dos agentes em participar da pesquisa e à possibilidade de acesso aos documentos e ao próprio espaço em que o evento acontece.

Após a escolha do evento, deve-se fazer um fluxo dos subeventos que o constituem. É esse fluxo que conduzirá a análise das demais etapas.

\subsubsection{Segundo passo: caracterização dos agentes, dos sistemas organizacionais e do contexto histórico, social e cultural que participam diretamente do evento escolhido}

Trata-se de um primeiro nível de análise que procura responder às seguintes questões:

- Quem são os agentes que participam diretamente do processo estratégico?

- Que elementos do contexto histórico, social e cultural e dos sistemas organizacionais são mobilizados pela ação desses agentes, identificados a partir da análise dos dados da pesquisa?

Para caracterizar os agentes, o pesquisador buscará responder a questões do tipo: I. quem são eles e qual a sua história de vida; 2. como atuam e que tipos de atividades realizam; 3. com quem interagem; 4. se são criativos, inovadores, orientados para realizações, ou passivos, conservadores e tendentes à conciliação com posições estabelecidas; 5 . se demonstram autonomia e independência ou conformidade, adaptação e dependência; 6 . quais são as suas principais capacidades e competências.

No nível de grupo, outras informações também são importantes: a composição do grupo, o tempo de permanência/fluidez, o grau de participação dos agentes e os interesses ou motivações que os unem.

A caracterização dos sistemas organizacionais implica descrever que regras e recursos da organização influenciaram diretamente nas ações do evento em análise, na perspectiva dos entrevistados. Durante o estudo na universidade foco da pesquisa, algumas questões salientaram-se, como os aspectos culturais relacionados às profissões, a busca por legitimidade e os jogos políticos existentes no interior da instituição, o que não significa que sejam sempre as mesmas em todos os eventos, pois isso dependerá de cada conjuntura.

$\mathrm{Na}$ caracterização, é possível descrever, de acordo com o evento em análise, por exemplo, os elementos da estrutura formal (no caso das universidades, como se apresentam a estrutura departamental e a colegiada, quantos níveis estruturais existem); da estrutura não formal (se existem comissões e como são formadas ou se existem equipes ou grupos constituídos a partir de projetos e como 
são formados); da cultura organizacional (que elementos/valores são comuns aos agentes, se existem crenças/valores diferenciadores do grupo em relação aos demais da organização, o que é valorizado na organização); formas de comunicação (frequência, uso ou não de tecnologias); e tomada de decisão (centralizada/ descentralizada, delegação, ausência).

A descrição do contexto deve salientar aspectos históricos, sociais e culturais que formaram a instituição como ela é hoje e que, na interpretação dos agentes, influenciaram determinado evento. Espera-se identificar que marcos institucionais constituíram determinada tradição. Podem ser os projetos de reforma, mudanças que resultaram em normas institucionalizadas e internalizadas, que passam de agente para agente em um processo de acumulação, que caracterizam a instituição em estudo. Devem-se também salientar aspectos legitimadores e as crises e oportunidades de momento enfrentadas pela organização. A abrangência dessa descrição está relacionada diretamente ao evento em análise. Um evento mais localizado em uma unidade ou grupo deverá focar o contexto mais relacionado com esse evento. A descrição também é limitada pelo relato dos entrevistados e dos documentos pesquisados.

\subsubsection{Terceiro passo: definição e análise integrada dos elementos do núcleo motriz da ação estratégica, a partir da percepção dos agentes}

Nessa fase, procura-se responder às seguintes questões:

- Como os agentes organizacionais agem e interagem?

- Como surgem e se desenvolvem as ações estratégicas a partir da combinação das três dimensões centrais do esquema?

Uma questão presente nessa fase é de que maneira os agentes percebem esse núcleo motriz em que a ação coletiva ocorre e como eles ajustam suas formas de agir a esse núcleo, ou melhor, como compatibilizam suas capacidades, competências e motivações na busca das estratégias de interesse de um determinado grupo.

\subsubsection{Quarto passo: utilização combinada do modelo com teorias organizacionais}

Para ampliar o número de "lentes analíticas", pode-se combinar a análise fundamentada no esquema analítico com outros modelos teóricos. 
Um quinto passo, opcional, pode ser acrescentado, no qual se estabelecem comparações entre os eventos, detalham-se as principais práxis resultantes e determinam-se os impactos dos eventos no fenômeno em estudo. Esse quinto passo requer uma pesquisa de caráter longitudinal.

\section{CONSIDERAÇÕES FINAIS}

O objetivo da pesquisa foi elaborar um esquema analítico capaz de apreender o fenômeno estratégico em sua complexidade, em uma perspectiva processual e prática. Desde o primeiro momento, houve a preocupação de obter coerência teórica e possibilidades de aplicação prática que trouxessem aportes ao conhecimento científico na área da administração e da análise estratégica.

Confirmou-se, primeiramente, não ser possível enquadrar esse tipo de processo em modelos analíticos concebidos a partir de abordagens monoparadigmáticas e unifocalizadas. A complexidade requer perspectivas mais ampliadas de análise capazes de integrar perspectivas macro, meso e micro-organizacionais de forma dinâmica.

Foi possível construir um esquema analítico do processo estratégico, a partir da proposta da visão geral, no qual os componentes podem ser visualizados de forma relacional.

No campo da prática da estratégia, foi possível delimitar a fronteira em que essa prática ocorre - em um núcleo motriz-estrutural, no qual se integram agentes, sistemas organizacionais e contexto (construído a partir da adaptação para os estudos organizacionais das teorias de Giddens (2003) e Sztompka (2005)). A delimitação do contexto de ação permite ao pesquisador uma melhor compreensão da intersubjetividade que une e conduz estrategicamente os agentes em torno de um objetivo.

As fases da pesquisa utilizando o esquema salientam aspectos fundamentais de uma pesquisa estruturacionista. A historicidade, por exemplo, foi capaz de delinear projetos anteriores na USP que, por razões diversas, não foram implementados, mas passaram a compor o conjunto de conhecimentos e experiências dos gestores mais antigos, influenciando-os no momento da elaboração da proposta do novo campus.

As regras do sistema social, compreendidas pelos agentes a partir de suas representações, concorreram para que um grupo de jovens doutores, recém-chegados ao ensino superior, privilegiasse os processos já legitimados nacionalmente na pós-graduação para desenvolver um projeto de mestrado que, de certa maneira, ia de encontro ao projeto pedagógico da nova unidade. 
O esquema foi testado e validado quando da análise de uma experiência real de elaboração e implementação de uma estratégia em uma universidade pública. Confirmou-se, entre outros aspectos, que a estratégia também ocorre no momento do desenvolvimento de eventos nem sempre planejados, assim como os agentes respondem de forma diferenciada conforme seus interesses, o que gerou (no caso estudado) modificações fundamentais nas intenções iniciais do projeto estratégico.

A tese de que as realidades organizacionais são construídas continuamente por meio de agentes em contextos de ação influenciando decisivamente o processo estratégico foi confirmada. Compreender as hábeis articulações por meio do qual esses agentes dão sentido aos seus atos é tarefa complexa que o esquema busca captar com a intenção de ser um caminho metodológico para os analistas organizacionais.

Reconhece-se que o fato de o esquema ter sido testado na análise de três eventos em uma mesma organização é um fator limitante, havendo necessidade de realizar novas pesquisas nas quais o esquema seja aplicado para considerar a sua validade.

Por fim, deve-se ressaltar que o melhor conhecimento do processo estratégico e da importância dos eventos na sua condução certamente poderá propiciar ao gestor reflexivo formas mais eficazes de condução estratégica nesse tipo de organizações, ensejando a continuidade dos estudos para verificar a possibilidade do desenvolvimento do esquema em uma abordagem prescritiva.

\section{PROPOSAL FOR AN ANALYTICAL FRAMEWORK FOR THE STRATEGIC PROCESS - THE CASE OF A PUBLIC UNIVERSITY}

\section{ABSTRACT}

The issue of capturing the dynamics of how strategic events occur and of identifying external and internal factors involved in their organization has been mobilizing researchers of the field for years. The objective of this paper is to present an analytical framework proposal on strategic process at a public university, in this case, the design and implementation of the Institutional Educational Project (IEP) of a new campus. From an analytical point of view, proceed from a less linear approach to a more interpretative strategy, in which its shaping occurs through social interaction, considering the beliefs and common interpretations of organizational members. Specifically, we intended to 
know how certain strategies emerge and the conjectural aspects which influence the prioritization and decision-making processes of its implementers. The proposal is based on the theories of Structure and Social Change (on the sociological field), and on the procedural and practical perspectives (on the organizational field). The scheme was built, implemented and validated during the implementation of a new university campus through qualitative research, using the case study methodology. This paper presents the preparation stage of the scheme. By undertaking a theoretical and methodological search that is able to subsidize descriptions and explanations of a dynamic process of creating and implementing strategies in a public university, we intended to find a way to comprehend the strategic phenomenon in an integrated manner, and not in a compartmentalized manner, as observed in many studies. Through the scheme, it was possible to realize the practical actions of the agents and their influence over the strategic process and how the way events develop can influence the practices of the strategists. It was possible to sense that agents in public universities use the power of their expertise to build a context favorable to their interests, even if this means significant changes in the IEP. For the organizational analyst, the blueprint is able to define levels of analysis in an integrated manner, temporally delimit the actions and outline methodological procedures.

\section{KEYWORDS}

Strategy. Strategic process. Analytical scheme. Public university. Social construction.

\section{MARCO ANALÍTICO PROPUESTO PARA EL PROCESO ESTRATÉGICO - EL CASO DE UNA UNIVERSIDAD PÚBLICA}

\section{RESUMEN}

Capturar la dinámica de los acontecimientos estratégicos que se producen e identificar los factores externos e internos a la organización que participan en la realización está movilizando hace años a los investigadores de campo. El objetivo de este trabajo es presentar el marco analítico propuesto en el proceso estratégico en una universidad pública, en este caso, el diseño y la implementación del Proyecto Educativo Institucional (PEI) de un nuevo campus. Desde el punto de vista analítico, se parte de un enfoque menos lineal para una estrategia más 
interpretativa, en la que su formación se produce a través de la interacción social, teniendo en cuenta las creencias e interpretaciones comunes de los miembros de la organización. Específicamente, se busca conocer cómo ciertas estrategias surgen y los factores de la coyuntura influyen en la fijación de prioridades y en la toma de decisiones de sus ejecutores. La propuesta se basa, en el campo sociológico, en las teorías de la Estructura y Cambio Social, y en el campo de la organización, en las perspectivas prácticas y de procedimiento. El esquema fue construido, implementado y validado cuando surge el episodio de la implementación de un nuevo campus universitario a través de la investigación cualitativa, utilizando la metodología de estudio de caso. En este trabajo se presenta la etapa de preparación del esquema. Al emprenderse una busca teórica y metodológica capaz de subsidiar descripciones y explicaciones sobre un proceso dinámico de creación e implementación de estrategias en una universidad pública se está tratando de encontrar la manera de aprovechar el fenómeno estratégico de una manera integrada, y no de manera compartimentada, como la que se observa en muchos estudios. Gracias a este plan fue posible llevar a cabo las acciones prácticas de los agentes y su influencia en el proceso estratégico y cómo la forma en que los acontecimientos se desarrollan influencia las prácticas de los estrategas. Se pudo intuir que los agentes en las universidades públicas utilizan el poder de su experiencia para construir un contexto favorable a sus intereses, incluso si eso implica cambios significativos en el PEI. Para el analista de la organización, el sistema es capaz de definir los niveles de análisis de forma integrada, delimitar de forma temporal las acciones y definir procedimientos metodológicos.

\section{PALABRAS CLAVE}

Estrategia. Proceso estratégico. Esquema analítico. Universidad pública. Construcción social.

\section{REFERÊNCIAS}

Ansoff, H. I. (I965). Corporate strategy: an analytic approach to business policy for growth and expansion. New York: McGraw-Hill.

Archer, M. (1982). Morphogenesis versus structuration: on combining structure and action. British Journal of Sociology, 33(4), 455-483.

Astley, G., \& Van de Ven, A. (2007). Debates e perspectivas centrais na teoria das organizações. In M. Caldas \& C. Bertero (Orgs.). Teoria das organizações (pp. 80-ıı6). São Paulo: Atlas.

Bastos, A. (2009). Cognição e ação nas organizações. In E. Davel \& S. Vergara. (Orgs.). Gestão com pessoas e subjetividade (pp. 8I-II4). São Paulo: Atlas. 
Bulgacov, S., Souza, Q., Prohmann, J., Coser, C., \& Baraniuk, J. (2007). Administração estratégica: teoria e prática. São Paulo: Atlas.

Chaffee, E. E. (1985). Three models of strategy. Academy of Management Review, 10(I), 89-98.

Chakravarthy, B., \& Doz, Y. (I992). Strategy process research: focus on corporate self-renewal. Strategic Management Journal, 13, 5-I4.

Collis, J., \& Hussey, R. (2005). Pesquisa em administração. Porto Alegre: Bookman.

Emirbayer, M., \& Mische, A. (1998). What is agency? The American Journal of Sociology, 103(4), 962-1023.

Freitas, M. J. (2007). Contexto social e imaginário organizacional moderno. Revista de Administração de Empresas, 40(2), 6-I5.

Giddens, A. (2003). A constituição da sociedade (2a ed.). São Paulo: Martins Fontes.

Jarzabkowski, P., \& Felton, E. (2006). Estrategizing and organizaing in pluralistic contexts. Longe Range Planning, 39, 631-648.

Johnson, G., Scholes, K., \& Whittington, R. (2007). Explorando a estratégia corporativa. Porto Alegre: Bookman.

Meirelles, A. M. (2003). Formação de estratégias no sistema bancário brasileiro. Tese de doutorado, Universidade Federal de Minas Gerais, Belo Horizonte, MG, Brasil.

Mintzberg, H. (1978). Patterns in strategy formation. Management Science, 29(9), 934-948.

Mintzberg, H. (2006). Criando organizações eficazes (2a ed.). São Paulo: Atlas.

Mintzberg, H., Ahstrand, B., \& Lampel, J. (2000). Safári de estratégia. Porto Alegre: Bookman.

Mintzberg, H., \& Waters, J. A. (1985). Of strategies, deliberate and emergent. Strategic Management Journal, 6(3), 257-72.

Oliveira, N. (20II). Entre Cila e Calíbdis: o realismo social de Margareth Archer. Sociologia, Problemas e Práticas, 65, II9-I39.

Pettigrew, A. M. (1987). Context and action in the transformation of the firm. Journal of Management Studies, 24(6), 649-670.

Pettigrew, A. M. (1992). The character and significance of strategy process research. Strategic Management Journal, 13, 5-16.

Sewell, W. H. (I992). A theory of structure: duality, agency and transformation. The American Journal of Sociology, 98(I), I-29.

Sztompka, P. (2005). A sociologia da mudança social. Rio de Janeiro: Civilização Brasileira.

Van de Ven, A. (1992). Suggestions for studying strategy process: a research note. Strategic Management Journal, 13, I69-188.

Van de Ven, A., \& Poole, M. S. (1995). Explaining development and change in organizations. Academy of Management Review, 20(3), 510-540.

Vasconcelos, I., Mascarenhas, A., \& Protil, R. (2004). Paradoxos na gestão de pessoas: cultura e contexto em uma cooperativa agroindustrial. Revista de Administração Eletrônica, 3(I), I-I9.

Whittington, R. (2004). Estratégia após o modernismo: recuperando a prática. Revista de Administração de Empresas, 44(4), 44-53.

Wilson, D., \& Jarzabkowski P. (2004). Pensando e agindo estrategicamente: novos desafios para a análise estratégica. Revista de Administração de Empresas, 44(4), II-20. 